Original Article

\title{
RANDOM ISED CROSS SECTIONAL STUDY OF ORAL HEALTH RELATED KNOWLEDGE AND BEHAVIOUR AMONG PARAMEDICAL STUDENTS
}

\author{
Shwethashri R Permi ${ }^{1}$, Rahul Bhandary ${ }^{2} \&$ Biju Thomas $^{3}$ \\ ${ }^{1}$ Post Graduate, ${ }^{2}$ Professor, ${ }^{3}$ Professor \&Head, Department of Periodontics, A.B. Shetty M emorial Institute of Dental \\ Sciences, Nitte University, Deralakatte, Mangalore, Karnataka, India \\ Correspondence : \\ Shwethashri R Permi \\ Post Graduate, Department of Periodontics, A.B. Shetty M emorial Institute of Dental Sciences, Nitte University, \\ Deralakatte, Mangalore - 575 108, Karnataka, India. \\ E-mail : harish.shwethashri@gmail.com
}

\begin{abstract}
:
The aim of the study is to estimate the knowledge, attitude and behaviour regarding oral health among para medical students

M aterials and method : A cross sectional questionnaire survey was conducted among 150 para medical professionals in $M$ angalore. The health care professionals include from physiotherapy, nursing and medical lab technicians. They were asked to answer a questionnaire that contained 15 questions regarding knowledge and behaviour towards oral health.

Results and conclusion : M ajority of para medical students were practising a convincing oral hygiene methods they believed oral health play a role in general health had a positive attitude in educating their patients when required.
\end{abstract}

Keywords: Paramedical students, questionnaire, oral health

\section{Introduction:}

Oral health is an important part of general health of body. Oral hygiene determines oral health status, thus its most important for good health in general, poor oral hygiene can be source of many disease .maintaining good oral hygiene practices we can prevent occurrence of dental caries , periodontal diseases etc, unfortunately oral hygiene practices are less emphasised in society ${ }^{(1,2,3)}$. Studies have shown that there is an association between increased knowledge and better oral health ${ }^{(4,5)}$.Those who have assimilated the knowledge and feel a sense of personal control over their oral health are more likely to adopt self care practices $^{(6)}$.

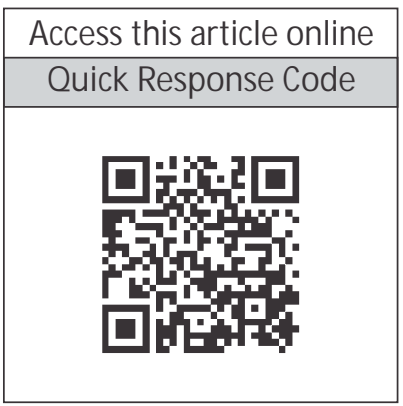

By virtue of their professional role, para medical personal play a vital role in health promotion and preventive information dissemination in community level. It is therefore important that their own oral knowledge is good and their oral health behaviour conforms to expectation of the population. The purpose of this study is to investigate oral health knowledge and behaviour among para medical students.

Objective: The aim of the study was to estimate the knowledge and behaviour regarding oral health among para medical students.

\section{Methodology:}

A cross sectional questionnaire survey was conducted among 150 para medical students in M angalore. The para medical health care students include from physiotherapy, Nursing and medical lab technicians. They were asked to answer a questionnaire that contained 15 questions regarding knowledge and behaviour towards oral health.

Ethical clearance was obtained from institutional ethical board of AB Shetty M emorial institute of dental science, $M$ angalore and written informed consent was taken from all the subjects prior for participation. 


\section{Statistical analysis:}

The data collected was analysed using statistical package for social sciences spss11.5version.the descriptive statistics like frequency distribution was calculated.

\section{Results:}

Table 1 reveals that 32\%of the respondents brush their teeth once daily and $64.7 \%$ brush twice a day, 3.3\%brush more than twice. None of the respondents used charcoal or neem, toothpowder etc $82.7 \%$ used toothpaste and brush, $17.3 \%$ used toothpaste, brush, floss . $4 \%$ of them used hard toothbrush where as $68.7 \%$ used medium bristle brush, $22 \%$ of them used soft brush, $5.3 \%$ didn't know the type of brush they used.4\% of the respondents practised horizontal brushing tecnique19\% used circular method, 7.3\% used vertical and majority of them practised combination of all.75.3\%were not aware of inter dental aids. This reveals the knowledge regarding oral hygiene measures.

Table 2 shows awareness about gingival health $36.7 \%$ noticed bleeding gums. 32\% complained of smell from mouth, $42 \%$ of the respondents were not aware of dental calculus.

Table 3 shows attitude towards professional dental care towards visiting dentist for

Table 1: Oral hygiene habits among Para medical students professional care $56 \%$ believed to visit dentist but $75.3 \%$ visited only when in pain , $71.3 \%$

\begin{tabular}{|l|c|c|}
\hline Brushing frequency & Frequency & Percentage \\
\hline Once daily & 48 & 32 \\
\hline Twice daily & 97 & 64.7 \\
\hline M ore than twice & 5 & 3.3 \\
\hline Oral hygiene materials used by paramedical professionals \\
\hline Materials used & Frequency & Percentage \\
\hline Toothpaste and brush & 124 & 82.7 \\
\hline Toothpaste and brush and floss & 26 & 17.3 \\
\hline \multicolumn{3}{|c|}{ Type of brush used } \\
\hline Type & Frequency & Percentage \\
\hline Hard & 6 & 4 \\
\hline Soft & 33 & 22 \\
\hline Medium & 103 & 68.7 \\
\hline Don't know & 8 & 5.3 \\
\hline
\end{tabular}

\begin{tabular}{|c|c|c|}
\hline Brushing frequency & Frequency & Percentage \\
\hline \multicolumn{3}{|c|}{ Brushing technique used } \\
\hline Technique & Frequency & Percentage \\
\hline Horizontal & 6 & 4 \\
\hline Circular & 29 & 19.3 \\
\hline Vertical & 11 & 7.3 \\
\hline Combined & 104 & 69.3 \\
\hline \multicolumn{3}{|c|}{ Awareness about interdental aids } \\
\hline & Frequency & Percentage \\
\hline Yes & 37 & 24.7 \\
\hline No & 113 & 75.3 \\
\hline
\end{tabular}

were not aware who periodontist are, $48 \%$ of respondent never got oral prophylaxis done $62.7 \%$ were completely unaware of any cosmetic gum treatment available .

Table 4 reveals that $91.3 \%$ believed that oral health effects general health and $84 \%$ believed in educating their patients whenever required $50.7 \%$ obtained all knowledge regarding oral health issues from schools and colleges.

Table 2: Awareness of oral health

\begin{tabular}{|c|c|c|}
\hline \multicolumn{3}{|c|}{ Ever noticed bleeding gums } \\
\hline & Frequency & Percentage \\
\hline Yes & 55 & 36.7 \\
\hline No & 95 & 63.3 \\
\hline \multicolumn{3}{|c|}{ Noticed smell from mouth } \\
\hline & Frequency & Percentage \\
\hline Yes & 48 & 32 \\
\hline No & 102 & 68 \\
\hline \multicolumn{3}{|c|}{ Do you know what dental calculus is } \\
\hline & Frequency & Percentage \\
\hline Yes & 85 & 56.7 \\
\hline No & 63 & 42.0 \\
\hline Thave heard about it & 2 & 1.3 \\
\hline
\end{tabular}

Table 3 : Awareness towards professional oral care among para medical students

\begin{tabular}{|c|c|c|}
\hline \multicolumn{3}{|c|}{ Do you visit dentist } \\
\hline & Frequency & Percentage \\
\hline Yes & 84 & 56 \\
\hline No & 66 & 44 \\
\hline \multicolumn{3}{|c|}{ how often do you visit dentist } \\
\hline & Frequency & Percentage \\
\hline Every 6 months & 16 & 10.7 \\
\hline Once a year & 21 & 14 \\
\hline When i have pain & 113 & 75.3 \\
\hline \multicolumn{3}{|c|}{ do you know who is periodontist are } \\
\hline & Frequency & Percentage \\
\hline Yes & 43 & 28.7 \\
\hline No & 107 & 71.3 \\
\hline
\end{tabular}




\begin{tabular}{|l|c|c|}
\hline \multicolumn{4}{|c|}{ have you got oral prophylaxis done } \\
\hline & Frequency & Percentage \\
\hline Yes & 78 & 52 \\
\hline No & 72 & 48 \\
\hline \multicolumn{4}{|c|}{ are you aware of cosmetic gum treatment } \\
\hline \multicolumn{4}{|c|}{ Frequency } & Percentage \\
\hline Yes & 56 & 33.7 \\
\hline No & 94 & 62.7 \\
\hline
\end{tabular}

Table 4 : Awareness regarding importance of oral health education

\begin{tabular}{|c|c|c|}
\hline \multicolumn{3}{|c|}{ Do you think oral health effect general health } \\
\hline & Frequency & Percentage \\
\hline Yes & 137 & 91.3 \\
\hline No & 13 & 8.7 \\
\hline \multicolumn{3}{|c|}{ Do you educate patients regarding oral health if required } \\
\hline & Frequency & Percentage \\
\hline Yes & 126 & 84 \\
\hline No & 24 & 16 \\
\hline \multicolumn{3}{|c|}{ From where do you obtain your information on } \\
\hline \multicolumn{3}{|c|}{ oral hygiene practice } \\
\hline & Frequency & Percentage \\
\hline From doctor/dentist & 35 & 23.3 \\
\hline From mass media & 39 & 26 \\
\hline From school/college & 76 & 50.7 \\
\hline
\end{tabular}

\section{Discussion :}

Oral diseases are considered a globally as public health issue due to high prevalence in society due to lack of education and skills. Role of para medical students as they are expected that they have good knowledge than

\section{References:}

1. Morenike Folayan, Ayomide Sowole, Aderonke Kola Jebutu. Risk factors for caries in children from south-western Nigeria. Journal of clinical paediatric dentistry 2007; 32:171-175

2. Goyala, Gaubak, Chawla H S, Kapur A. Epidemiology of dental caries in Chandigarh school children and trends over the last 25 years.J Indian soc pedo prev Dent.2007;25:115-118.

3. Dhar V, Jain A, Van Dyke T E, Kholi A. Prevalence of dental caries and treatment needs in the school going children of rural areas in Udaipur district. Indian Soc Pedo prev Dent 2007; 25:119-121.

4. Woodgroove J, G.Cumberbatch, S.Gylbier. Understanding dental attendance behaviour. Community Dent Health 1987; 4:215-221.

5. Hamilton. M. E, W.M.Coulby. Oral health knowledge and habits of senior elementary school students. Journal of Public Health Dentistry 1991; 51:212-219.

6. Freeman R, J.M aizels, M.Wyllie, A.Sheiham. The relationship between health related knowledge, attitude and dental health behaviour in 1416-year-old adolescents. Community Dental health 1993; 10:.397404.

7. Laxman Singh Kaira, Virag Srivastava, Parul Giri, Devendra Chopra. Oral health-related knowledge, attitude and practice among nursing students of Rohilkhand M edical College and Hospital; A questionnaire study, 10.5005/JP-journals-10026-1005. community apart which can be imparted during their practise for betterment of their patients.

Oral hygiene is a prime key to healthy mouth .This study population had good knowledge and awareness of oral hygiene practises, materials and usage of same, issues regarding bleeding gums, $32 \%$ of them complained of smell from oral cavity. They had a positive attitude in seeking dental professional help, in contrast majority of them visited dentist only in pain. The results of present study are similar to study conducted by laxman singh ${ }^{(7)}$. $91.3 \%$ respondents understand that there exist a link between oral and systemic health and they acquired this knowledge through school and colleges, mass media. The oral health education and motivation if emphasised in their study period, this knowledge can be imparted to their patients in nearfuture for better health.

\section{Conclusion :}

This study showed an overview of oral health related knowledge attitude and practise behaviour among paramedical students the knowledge and attitude towards oral health is good, but can be emphasised more through education as para medical students play a vital role in health education promotion and prevention in community level. 